\title{
Maternal Hypovitaminosis D with Neonatal Convulsions
}

Sir,

Maternal Vitamin D deficiency has been reported in Indian women of lower socioeconomic class and in Asians in temperate climates. ${ }^{1,2}$ Reports on neonatal hypocalcemic seizures as a result of maternal vitamin $\mathrm{D}$ deficiency in well nourished upper socio-economic class mothers living in tropical areas are rare. One-mthold male (full term, $3 \mathrm{~kg}$ ) presented with abnormal movements of limbs since 15 days of life. Family hailed from Latur (Maharashtra, latitude $18.7^{\circ} \mathrm{N}$ ) and mother had four pregnancies in five years. Antenatal history was insignificant and baby was exclusively breastfed. Movements were intermittent, clonic, involving face, then hands and feet, lasting 1-2 min (1-2 episodes/ day), no history of lethargy, vomiting, fever, refusal to feed or rash. He was diagnosed to have hypocalcemia and had received calcium infusion, $3 \mathrm{wk}$ before he came to us.

There were no significant findings on examination, mother was well nourished (BMI $\left.27 \mathrm{Kg} / \mathrm{m}^{2}\right)$ and had no symptoms of bone ill health. Hematology, liver function, electrolytes, blood sugar, lumbar puncture, blood culture, chest X-ray, abdominal ultrasound and infantogram were normal. Mother's total serum calcium (tCa) was $8.71 \mathrm{mg} / \mathrm{dl}$ (8.8-11), ionized calcium (iCa) was $3.6 \mathrm{mg} / \mathrm{dl}$ (4.48-5.28) (ion selective auto analyser), inorganic phosphorous (iP)was $3.87 \mathrm{mg} / \mathrm{dl}$ (4.5-5.5), alkaline phosphatase (ALP) was 149 IU (200-645 IU/L) (Semi auto analyser (Biotech, USA)), intact parathyroid hormone (PTH) was $210 \mathrm{pg} / \mathrm{ml}$ (10-76) ( enzyme Immunoassay technique (BioSource Europe S.A))and 25 $(\mathrm{OH})$ Vitamin D (25OHD) was 5ng/dl(19-28) ( radioimmunoassay (DiaSorin, Stillwater, Minnesota, USA)).

Baby's bone health parameters on Day1 showed very low tCa $(4.6 \mathrm{mg} / \mathrm{dl}), \mathrm{iCa}(2.2 \mathrm{mg} / \mathrm{dl})$ and 25OHD (2.9 $\mathrm{ng} / \mathrm{dl}$ ), raised iP10.6 mg/dl, ALP $2015 \mathrm{IU}$ and PTH $(188 \mathrm{pg} / \mathrm{ml})$. Treatment was initially with IV fluids, phenobarbitone (10mg bd), antibiotic (ceftriaxone) and calcium gluconate (infused IV $8 \mathrm{ml}$ as $1: 1$ dilution 8 hourly for 5 days). 1-25 dihydroxy vitamin D3 0.25 microgram was started twice a day. Baby had no convulsive episodes after 2 days of treatment and was discharged on vitamin D3 and calcimax $4 \mathrm{ml}$ twice a day (150 mg elemental calcium/ $5 \mathrm{ml}$ ).

At discharge biochemistry showed tCa $7.3 \mathrm{mg} / \mathrm{dl}$ iCa $3.6 \mathrm{mg} / \mathrm{dl}$, iP $8.9 \mathrm{mg} / \mathrm{dl}$ and at follow up (Day 23) they were tCa $9.8 \mathrm{mg} / \mathrm{dl}$, iCa $4.4 \mathrm{mg} / \mathrm{dl}$, iP $5.8 \mathrm{mg} / \mathrm{dl}$, ALP $360 \mathrm{iu}, 25 \mathrm{OHD} 20 \mathrm{ng} / \mathrm{dl}$, PTH 60 pg/ml. i.e., all normal For an exclusively breastfed baby, the main source of vitamin D is breast milk $(20-60 \mathrm{IU} / 1){ }^{3}$ Vitamin D stores of the newborn largely depend on maternal stores, hence, in a vitamin D-deficient mother, the infant will be deficient because of decreased maternal fetal transfer. ${ }^{4}$ The mother of our patient came from the upper socioeconomic class and was living in a sun rich area of India. We speculate that her low vitamin $\mathrm{D}$ levels were a result of multiple pregnancies and also, probably due to low sunshine exposure during pregnancy. Very few foods in India are fortified with vitamin $\mathrm{D}$ and adequate vitamin D supplementation of mothers should be considered irrespective of socio economic status.

V.V. Khadilkar, S. Rajadhyaksha ${ }^{1}$ and A.V. Khadilkar

${ }^{1}$ Denanath Mangeshkar Hospital, Pune Growth and Pediatric Endocrine Unit, Hirabai Cowasji Jehangir Medical Research Institute, Jehangir Hospital, 32, Sassoon Road, Pune-411001, India. E-mail: akhadilkar@vsnl.net,vamankhadilkar@gmail.com

[DOI: 10.1007/s12098-009-0306-8]

\section{REFERENCES}

1. Balasubramanian S, Ganesh R. Vitamin D deficiency in exclusively breast-fed infants. Indian J Med Res 2008 ; 127: 250-255.

2. Alfaham M, Woodhead S, Pask G, Davies D. Vitamin D deficiency: a concern in pregnant Asian women. Br J Nutr 1995; 73: 881-887.

3. Hollis BW, Roos BA, Draper HH. Vitamin D and its metabolites in human and bovine milk. J Nutr 1981; 111: 1240-1248.

4. Salle BL, Delvin EE, Lapillonne A, Bishop NJ, Glorieux FH. Perinatal metabolism of vitamin D. Am J Clin Nutr 2000; 7: 1317S-1324S. 